\title{
Design and evaluation of transportation networks: constructing transportation networks from perspectives of service integration, infrastructure investment and information system implementation
}

\author{
Xiaoning Shi • Thierry Vanelslander
}

Published online: 1 June 2010

(C) Springer Science+Business Media, LLC 2010

Many enjoy services that are provided by current transportation networks worldwide. Meanwhile, researchers are engaged in further improving the transport services by various means, e.g., service integration, infrastructure investment and information systems implementation. The main aims of such improvements would be to enhance human well-being, eliminate externalities, facilitate decision making processes, etc.

In an attempt to show readers of this journal, especially those who major in kinds of perspectives of transportation, a number of critical ideas and cases demonstrating how transport research can be of help both in daily business and policy making, this special issue on Design and Evaluation of Transportation Networks was set up.

Firstly, it is now clear that the transportation business features vertical and horizontal integration together with competition [1, 2]. Transportation networks are then constructed from the infrastructural perspective as well

\footnotetext{
X. Shi $(\varangle)$

Institute of Information Systems, University of Hamburg,

Von-Melle-Park 5, 20146 Hamburg, Germany

e-mail: shi@econ.uni-hamburg.de

X. Shi

Shanghai Jiao Tong University, 1954 Hua Shan Road,

Shanghai 200030, People's Republic of China

T. Vanelslander

Department of Transport and Regional Economics, University of Antwerp,

Prinsstraat 13, 2000 Antwerpen, Belgium

e-mail: thierry.vanelslander@ua.ac.be
} 
as from the service perspective. Since the start of the current financial crisis, the on-going integration within the transportation industry, to a great extent, seems to have come to a temporary halt. However, if we have a look at what the research \& development departments of nearly all transport service providers are now focusing on, the cumulated power of the next round of integration and competition can be felt and a reboot of infrastructure investment is to materialize as soon as the economy situation turns brighter again. In the meantime, many transportation providers may not survive the economic downturn. This short-run perspective is not the core focus of this special issue. However, some of its papers put attention to short-run issues, like the elastic demand of facility factors, the analysis of what is extremely valuable in view of the current overcapacity situation and similar factors.

Secondly, from the perspective of information systems implementation, many actors involved in the transportation networks are eager to construct or implement more effective and efficient decision support systems and appropriate portals. This kind of decision support tools seems indispensable to reach the aforementioned service integration in a smooth way. However, there are some practical issues that need attention. For instance, a conflict on data sharing might occur between those business-related agents. Imagine that a liner shipping company, as one of the papers in this special issue mentions, would make her operational and consequent financial analysis based on the fleet schedule, but that port operators would not like to share their operational details with the liner shipping carrier during the negotiation procedures. Hence, it would be hard for the liner to choose ports of call and consequently to optimize its schedule. Another instance of such conflict of data sharing could be the reluctance to co-operate with adjacent local authorities, especially when they are governing almost the same hinterland. Regional or local authorities could be of help to implement for instance a common information platform. If such co-operation is not possible, it might be hard to reach optimal planning from the perspective of many of the chain players involved, which is detrimental to the entire supply chain in the end. Equally, such tool could be of great help to governments in optimally planning their ports and hinterland connections.

Thirdly, specific interest goes to the perspective of passenger transportation. The environment needs to be protected in different ways, and releasing less green house gas (GHG) might be one of the most popular ways. One contribution in this special issue, directly or indirectly, provides food for thought on how better public mass transit networks could be designed, without ignoring passengers' well-being, so that more and more passengers are selfmotivated to taking public mass transit instead of using less-environmentalfriendly transport modes.

In this context, this special issue of Design and Evaluation of Transportation Networks includes a collection of outstanding papers, made after a thorough selection and refereeing process. This special issue covers topics at the cutting edge of transportation research: evaluating transport mode decision making by taking into account user's happiness; designing liner shipping services by taking 
into account cooperative stability; setting pricing policy of a short sea shipping service; using information systems to support ocean-sea shipping services; and comparing different strategies of port operators along adjacent geographic ranges.

The first paper, on a New Approach in Transportation Planning: Happiness and Transport Economics, by André Duarte, Camila Garcia, Grigoris Giannarakis, Susanna Limão, Amalia Polydoropoulou and Nikolaos Litinas, analyses the relationships between happiness and transport economics in terms of incorporating well-being measurement when choosing between a private and a public transport mode, e.g., between owned car and metro. This paper proposes a novel idea in applying behavioural analysis together with psychology in transport economics analysis. The approach seems very promising and interesting, though this respect has not yet been heavily stressed by previous research. This paper can be regarded as a good example of how human behaviour affects transport economics as well as the other way around.

The second paper, on an Integrated Approach for Port Selection Ship Scheduling and Financial Analysis, by Jasmine Siu Lee Lam, researches the popular topic on the ship routing and scheduling problem at both planning level and operational level, taking into account the financial analysis and market dynamics simultaneously. An integrated intelligent system is designed and demonstrated to support the decision making process. Therefore, the demonstration of this Decision Support System (DSS) is of great interest to the liner shipping carrier.

The third paper, on Short Sea Shipping Intermodality and Parameters Influencing Pricing Policies: The Mediterranean Case, by Monica Grosso, Ana-Rita Lynce, Anne Silla and Georgios K. Vaggelas, begins with the identification of factors and/or parameters influencing the pricing policy and the cost structure of intermodal transport. An overview of current policy is also made. Later on, a questionnaire is applied as a means to collect data and observe different elements that are influencing price and cost. The way that the authors implement interviews as well as the results of this paper can be very useful for the peers who are to examine the pricing scheme and the cost structure of intermodal transportation.

These papers mentioned above were presented at the first TRANSPORTNET Seminar (Dec 2007) in Chios, Greece, the International Association of Maritime Economists annual conference (Apr 2008) in Dalian, China, the Italian Congress of Transport Economists (Jun 2008) in Sassano, Italy, and the Swiss Transport Conference (Oct 2007) in Switzerland. The various papers benefited from the many constructive comments and suggestions made during those conferences.

We would also like to stress that the successful implementation of this special issue owes to a whole range of individuals, including not only the enthusiastic authors but also the patient and knowledgeable referees who have spent lots of time and effort to provide valuable suggestions and comments. We would like to thank again the referees who have contributed in this special issue. 
Last but not least, we would like to express our gratitude to the TRANSPORTNET Marie Curie Program under the 6th Framework of the European Union, which provided most of the authors with enormous opportunities to advance their research in terms of attending conferences and organizing research related activities, of which the contributions in this issue are a valuable proof.

\author{
Xiaoning Shi \\ Thierry Vanelslander \\ Guest editors \\ February 2010
}

\title{
References
}

1. Shi, X., \& Voß, S. (2007). Container terminal operations under the influence of shipping alliances. In K. Bichou, M. G. H. Bell, \& A. Evans (Eds.), Risk management in port operations, logistics and supply chain security (pp. 135-167). London: Lloyd's List.

2. Van de Voorde, E., \& Vanelslander, T. (2009). Market power and vertical and horizontal integration in the maritime shipping and port industry. Paris: OECD, Joint Transport Research Centre (Discussion paper/OECD; 2009-2). 